\title{
Blastocystis sp. and Other Intestinal Parasites in Hemodialysis Patients
}

\author{
Rose Anne Kulik ${ }^{1}$, Dina Lúcia Morais Falavigna ${ }^{2}$, Letícia Nishi ${ }^{3}$ and Silvana Marques Araujo ${ }^{2,3}$ \\ ${ }^{1}$ Faculdade Integrada of Campo Mourão; ${ }^{2}$ Post Graduation Program in Clinical Analysis; ${ }^{3}$ Post Graduation Program in Sciences of Health; \\ State University of Maringá; Maringá, PR, Brazil
}

\begin{abstract}
Chronic renal insufficiency disease (CRI) leads to uremia in hemodialysis patients and induces a state of immunodepression that results in higher frequencies of infections and diarrhea. Hemodialysis patients resident in the city of Campo Mourão, Paraná, Brazil were analyzed from April 2006 through September 2007 for Blastocystis sp. and other intestinal parasites and for associated diarrhea. Fecal samples from 86 hemodialysis patients and 146 healthy (reference) persons were examined by standard methods for detecting ova, larvae and cysts, which included preservation in $\mathbf{1 0 \%}$ formalin and the Kinyoun method. Thirty-three hemodialysis patients $(\mathbf{4 5 . 1} \%)$ and 36 reference individuals $(25.7 \%)$ were found to be parasitized. The differences in the percentages of parasitism and polyparasitism between the reference group and the chronic renal patients was significant $(p=0.0318$ and 0.0019, respectively). Blastocystis sp. (18\%-20.1\%), Endolimax nana (14\%-16.3\%), Cryptosporidium sp. (4\%-4.7\%) and Entamoeba coli (4\%-4.7\%) were the most frequent protozoa found in the hemodialysis patients. Parasitism was not significantly associated with diarrhea $(p=0.9947)$ or with decreased white blood cell counts $(p=0.7046)$ in these individuals. Because parasitic infections may be an important comorbidity factor in hemodialysis patients, we suggest that parasitological stool examinations, especially for Blastocystis sp. and Cryptosporidium sp., be included in routine medical follow-up examinations of these patients.
\end{abstract}

Key-Words: Blastocystis sp., hemodialysis patients, parasites.

Increased life expectancies and the resulting aging of many human populations have increased the incidence of chronic degenerative diseases, such as chronic renal insufficiency (CRI) [1]. CRI causes progressive and irreversible loss of renal function, in which the human body does not maintain metabolic and hydroelectrolytic equilibrium. The accumulation of nonexcreted metabolites by the kidney, such as urea [2], which leads to uremia [3], is one of the complications of CRI. Uremia induces a natural state of immunodepression, most commonly expressed as negativity to delayed hypersensitivity skin tests and an increase in the incidence of infections [4,5], which are responsible for $48 \%$ of deaths in patients with CRI $[3,6]$.

Although disease manifestations do not exempt any organic system, diarrhea is one of the most important clinical signs of CRI [2]. In immunocompromised individuals, parasitic infections can cause profuse diarrhea, usually accompanied by weight loss, anorexia, malabsorption syndrome, and in some cases, fever and abdominal pain [5]. Blastocystis sp. [7,8], Cryptosporidium sp., Entamoeba histolytica and Giardia duodenalis are protozoan parasites that can cause diarrhea in humans [9-11], although Blastocystis sp. is often undiagnosed [12].

Blastocystis sp. is a pathogenic agent in immunodepressed or immunosuppressed individuals, causing symptomatic or asymptomatic infections $[13,14]$. Water, pets, and raw vegetables can be sources of infection [15]. The prevalence of this parasite ranges from 1.5 to $15 \%$ in developed countries, and from 30 to $50 \%$

Received on 10 April 2008; revised 8 July 2008.

Address for correspondence: Dr. Dina Lúcia Morais Falavigna. Bloco I-90, sala 11 - Universidade Estadual de Maringá. Zip code: 47020900. Maringá - PR, Brazil. Phone: (44) 3224 5688/ 9925 3508. Fax number: (44) 3261 4860. E-mail: falavigna@wnet.com.br.

The Brazilian Journal of Infectious Diseases 2008;12(4):338-341. (C) 2008 by The Brazilian Journal of Infectious Diseases and Contexto Publishing. All rights reserved. in developing countries [15,16]. Several therapeutic agents available for the etiological treatment of intestinal protozoa can improve the clinical condition and quality of life of patients with CRI $[13,14]$.

We assessed the prevalence of Blastocystis sp. and other intestinal parasites, and investigated whether these infections are associated with diarrhea in patients undergoing hemodialysis in the city of Campo Mourão, state of Paraná, Brazil.

\section{Material and Methods}

This project received approval by the Permanent Committee for Ethics in Research with Human Beings of our institution - Copep/UEM (Protocol CAAE 01210093000-05; Assessment No. 220/2005).

All 86 hemodialysis patients attended at the Instituto do Rim (Kidney Institute) in Campo Mourão from April 2006 through September 2007 were included in our study. The patients ranged from 21 to 82 years old, with a mean of $47.9 \pm 16.8$ years for females $(40.2 \%)$ and $50.4 \pm 13.7$ years for males (59.8\%).

Fecal exam results for 146 reference individuals, who lived in the same district, did not have kidney problems, were in the same age range and proportion of sexes, and were attended at local public health centers, were used for comparison. Neither the occurrence of diarrhea nor changes in white blood cell counts were investigated in the reference group.

The fecal samples were obtained after the person signed a form acknowledging informed consent. Three fecal samples were collected from each individual, on non-consecutive days. The fresh fecal material was stored in wide-mouth flasks with threaded lids. These flasks were labeled with the name of the person, delivery date and protocol number. The correct way to collect and store the feces was explained to the persons when the flasks were given to them.

The fresh fecal samples were analyzed with the Faust, Lutz and Rugai methods [17]. A portion of each sample was stored 
in a $10 \%$ formalin solution at a proportion of 1:1 to analyze for Cryptosporidium sp. and Blastocystis sp. We used direct smears made from these formalin-preserved samples to inspect for cysts of Blastocystis sp., and we used the modified Kinyoun acid-fast staining method to detect Cryptosporidium sp. [17]. CRI patient blood count (number of leukocytes) data were obtained from medical records based on examinations made during the same period at the Instituto do Rim.

Statistical analyses were performed using Statistica version 6.0. The chi-square test was used to compare the prevalence of enteroparasites in hemodialysis patients and the reference group, the characteristics (except for age) of CRI individuals undergoing hemodialysis who had or did not have intestinal parasites, and to test for a possible association between these parasites and diarrhea. Student's t test was used to compare the mean ages of the individuals in these groups. The significance level adopted was 5\%.

\section{Results}

Among the 86 hemodialysis patients, 33 (45.1\%) had parasites (Table 1) and eight (9.2\%) had more than one species of parasite. Blastocystis sp. (18\%-20.1\%), Endolimax nana (14\%-16.3\%), Cryptosporidium sp. (4\%-4.7\%) and Entamoeba coli (4\%-4.7\%) were the most frequent protozoa (Table 2).

Both Blastocystis sp. and E. nana were found in seven patients (21.2\%), and E. nana and E. coli in one $(3.0 \%)$. Diarrhea was diagnosed in two of the seven patients infected with Blastocystis sp. and E. nana, and in the patient who had both E. nana and E. coli.

Among the 146 individuals in the reference group (Table 1), monoparasitism (23 cases-25.7\%) predominated over polyparasitism (13 cases- $0.9 \%$ ). The most frequent parasites were Iodamoeba bütschlii, Enterobius vermicularis, Ascaris lumbricoides, Hymenolepis nana, Trichuris trichiura and Taenia sp.

Differences in the percentages of parasitism and polyparasitism between the reference group and the hemodialysis patients were significant ( $p=0.0318$ and 0.0019 , respectively).

Among the 76 hemograms, 16.4\% (13) indicated leucopenia, 7.6\% (6) leucocytosis and 7.6\% (6) neutrophilia. The finding of parasites was not significantly related $(p=0.7046)$ to changes in white blood cell counts (Table 3). Among the 33 parasitized hemodialysis patients, 25 had diarrhea (Table 4). There was no significant association between diarrhea and parasitism ( $\mathrm{p}=0.9947)$.

\section{Discussion}

There have been several studies on the incidence of parasites in populations of immunodepressed and/or immunosuppressed individuals, mainly those with HIV [1822]. However, there is little information on kidney patients $[9,10,23,24]$. We found that parasitism and polyparasitism were more frequent in hemodialysis patients than in the reference group. Parasitism was more closely related to the degree of compromise of the immune system in these patients than to exposure to pathogens transmitted via the fecal-oral route; the latter is more important in the immunocompetent population $[10,23]$. This may be a consequence of the careful orientation about diet given to these patients; they are advised to eat well-cooked greens, vegetables and meat [25] in order to avoid parasitosis. These precautions could explain the absence of parasites such as I. bütschlii, E. vermicularis, $A$. lumbricoides, $H$. nana, T. trichiura and Taenia sp. in the hemodialysis patients, compared to the reference group.

Blastocystis sp. has a worldwide distribution, appearing more frequently in tropical and subtropical countries [26]. There are no reports of blastocytosis cases in hemodialysis or kidney-transplant patients in the Brazilian literature. In our study, $20.1 \%$ of the hemodialysis patients were infected with Blastocystis sp. Although infections by this protozoan have been related to poor-quality drinking water [15,27], it is unlikely that these patients acquired the parasites from contaminated water, because treated water is supplied to nearly $100 \%$ of the population of Campo Mourão [28].

Individuals who are undergoing dialysis treatments have a high risk of acquiring infections through contact with nursing staff, equipment and materials, on surfaces or from hands [29]. These patients, already immunodepressed because of their condition, become more susceptible after repeated hospitalizations and as a result of surgical interventions that may be required [30].

The incidence of $E$. nana was significantly higher in the dialysis patients compared to the reference group, again probably a result of the immunological fragility of these patients. In immunodepressed and/or immunosuppressed individuals, E. nana causes irritation of the crevices of the intestinal mucosa, progressing to fibrosis, with impaired absorption of food, causing gastrointestinal symptoms such as diarrhea [31].

The frequency of Cryptosporidium sp. in the hemodialysis patients was relatively lower (4.6\%) than that reported by Seyrafian et al. (2006) in Iran, and by Turkcapar et al. (2002) in Turkey, who reported $11.5 \%$ and $20.27 \%$, respectively, in adult patients. This may be a consequence of the quality of drinking water [9-11,24], because in Brazil, all water used by the population is subject to quality control [2]. Reinforcing this hypothesis, Chieffi et al. (1996) in a study of immunocompromised individuals in Brazil reported a frequency of infection of Cryptosporidium sp. similar to what we found.

Blastocystis sp. and E. nana were found together in 21\% of the hemodialysis patients studied. In mixed or single infections, they may be related to diarrhea, especially when they are abundant in patients [31,32]. The presence of these parasites in the gastrointestinal tract modulates the immune response, predisposing to infection with other enteropathogens and favoring secondary infections and multi-parasitism [31].

Cases of leucocytosis and/or leucopenia, such as those we found in our study, may occur in simple infectious processes, such as pharyngoamygdalitis, not necessarily associated with parasitism [34]. However, the white blood cell counts and neutrophilia found in some of the hemodialysis 
Table 1. Prevalence of enteroparasites in hemodialysis patients and in the reference group.

\begin{tabular}{lccccr}
\hline Parasites & \multicolumn{2}{c}{ Hemodialysis patients } & & \multicolumn{2}{c}{ Reference group } \\
\cline { 2 - 3 } \cline { 5 - 6 } & $\mathbf{N}$ & $\mathbf{\%}$ & & $\mathbf{N}$ & $\mathbf{\%}$ \\
\hline Positive & $33^{*}$ & 45.1 & $36 *$ & 26.7 \\
Negative & 53 & 55.0 & & 110 & 73.3 \\
Total & 86 & 100.0 & 146 & 100.0 \\
* $\mathrm{p}=0.0318$ (chi-square test; significance level of 5\%). & & &
\end{tabular}

Table 2. Prevalence of enteroparasites by species, in hemodialysis patients and in the reference population.

\begin{tabular}{|c|c|c|c|c|c|}
\hline \multirow[t]{2}{*}{ Parasite species } & \multicolumn{2}{|c|}{ Hemodialysis patients } & \multicolumn{2}{|c|}{ Reference group } & \multirow[t]{2}{*}{$\mathbf{p}^{* *}$} \\
\hline & $\mathbf{N}$ & $\%$ & $\mathbf{N}$ & $\%$ & \\
\hline Blastocystis sp. & 18 & 20.9 & $\mathrm{Nd}$ & - & - \\
\hline Endolimax nana & 14 & 16.3 & 2 & 1.1 & 0.0001 \\
\hline Cryptosporidium sp. & 2 & 4.7 & $\mathrm{Nd}$ & - & - \\
\hline Entamoeba coli & 4 & 4.7 & 3 & 1.7 & 0.2873 \\
\hline Strongyloides stercoralis & 2 & 2.3 & 1 & 0.6 & 0.2977 \\
\hline Giardia duodenalis & 1 & 1.2 & 2 & 1.1 & 0.8866 \\
\hline Other parasites * & 0 & 0 & 28 & 21.2 & 0.0001 \\
\hline
\end{tabular}

Table 3. Characteristics of chronic renal insufficiency patients undergoing hemodialysis, according to the presence or absence of intestinal parasites.

\begin{tabular}{|c|c|c|c|c|c|}
\hline \multirow[t]{2}{*}{ Characteristics } & \multicolumn{2}{|c|}{ Parasitized } & \multicolumn{2}{|c|}{ Non-parasitized } & \multirow[t]{2}{*}{$\mathbf{p}$} \\
\hline & $\mathbf{N}$ & $\%$ & $\mathbf{N}$ & $\%$ & \\
\hline Age (mean) & $45.9 \pm 13.8$ & & $51.5 \pm 15$ & & $0.046538 *$ \\
\hline \multicolumn{6}{|l|}{ Gender } \\
\hline Male & 17 & 51.5 & 33 & 62.3 & $0.6454 * *$ \\
\hline Female & 16 & 48.5 & 20 & 37.7 & $0.5020 * *$ \\
\hline \multicolumn{6}{|l|}{ Hemogram } \\
\hline Leucopenia & 4 & 12.1 & 9 & 17.0 & $0.5506 * *$ \\
\hline Leucocytosis & 3 & 9.1 & 3 & 5.7 & $0.6127 * *$ \\
\hline Neutrophilia & 0 & $0 \%$ & 6 & 11.3 & $0.0533 * *$ \\
\hline \multicolumn{6}{|l|}{ Diarrhea } \\
\hline Present & 25 & 75.8 & 40 & 75.5 & $0.9911 * *$ \\
\hline Absent & 8 & 24.2 & 13 & 24.5 & $0.9813^{* *}$ \\
\hline Examined patients (N) & \multicolumn{2}{|c|}{33} & \multicolumn{2}{|c|}{53} & \\
\hline
\end{tabular}

Statistical comparisons were carried out by Student's t* or chi-square test**; significance level of 5\%.

Table 4. Association between the presence of parasites and diarrhea in hemodialysis patients.

\begin{tabular}{|c|c|c|c|c|c|}
\hline \multirow[t]{3}{*}{ Parasite } & \multicolumn{4}{|c|}{ Diarrhea } & \multirow[t]{3}{*}{$\mathbf{p}^{*}$} \\
\hline & \multicolumn{2}{|c|}{ Present } & \multicolumn{2}{|c|}{ Absent } & \\
\hline & $\mathbf{N}$ & $\%$ & $\mathbf{N}$ & $\%$ & \\
\hline Blastocystis sp. & 11 & 61.1 & 7 & 38.9 & 0.2726 \\
\hline Endolimax nana & 8 & 57.1 & 6 & 42.9 & 0.2019 \\
\hline Cryptosporidium sp. & 2 & 100.0 & 0 & 0.0 & 0.4279 \\
\hline Entamoeba coli & 4 & 100.0 & 0 & 0.0 & 0.2660 \\
\hline Strongyloides stercoralis & 2 & 100.0 & 0 & 0.0 & 0.4279 \\
\hline Giardia duodenalis & 1 & 100.0 & 0 & 0.0 & 0.5734 \\
\hline Total & \multicolumn{2}{|c|}{25} & \multicolumn{2}{|c|}{8} & 0.9947 \\
\hline
\end{tabular}

*Chi-square test; significance level of 5\%. 
patients in our study are indicative of immunodepression, which can increase susceptibility to parasitosis [2,27]. Infections may cause or worsen anemia in hemodialysis patients, aggravating immunodepression. This underscores the need for early diagnosis of parasitosis and treatment to minimize its impact on the patient [35].

The frequency of diarrhea in our hemodialysis patients was not significantly different from that of the patients without parasites. However, Blastocystis sp. and E. nana may be considered pathogenic, especially when they provoke diarrhea and other diarrheagenic agents are excluded [31-33]. Thus, when diagnosed, these patients must be treated [14], since subclinical infections may appear in about two-thirds of individuals who undergo kidney transplants [13]. The combination of drugs used to prevent organ rejection, markedly favors reactivation of the protozoosis, leading to persistent diarrhea and dysentery [13,33].

The effects of currently-available treatments and procedures for handling chronic diseases on the epidemiology of infectious agents, such as Blastocystis sp., which has been ignored for many decades by health professionals, deserves consideration. We suggest that parasitological stool examinations with emphasis on Blastocystis sp. and Cryptosporidium sp. be included in routine follow-up exams of individuals undergoing hemodialysis. In addition, repetition of parasitological tests is necessary to establish the etiology of the diarrheal crisis, or to detect possible asymptomatic hosts, especially in hemodialysis patients, since the drugs used to treat protozoosis are not always effective against blastocystosis and cryptosporidiosis.

\section{References}

1. Lessa I. Doenças crônicas degenerativas. In: Rouquayrol MZ. Epidemiologia \& saúde. Editor Medsi. 5th ed. Rio de Janeiro; 1999. p. 411-5.

2. NKF-KDOQI. Clinical practice guidelines for chronic kidney disease: evaluation, classification, and stratification. Am J Kidney Dis 2002;39:S1-266.

3. Marques A.B., Pereira D.C., Ribeiro R.C.H.M. Motivos e freqüência de internação dos pacientes com IRC em tratamento hemodialítico Arq Ciênc Saúde 2005;12(2):67-72.

4. Kauffman C.A., Manzler A.D, Phair J. P. Cell-mediated immunity in patients on long-term haemodialysis. Clin Exp Immunol 1975;22:54-61.

5. D’Avila R., Guerra E.M.M., Rodrigues C.I.S., et al. Sobrevida de pacientes renais crônicos em diálise peritoneal e hemodiálise. J Bras Nefrol 1999;21(1):13-21.

6. Barbosa D.A., Gunji C.K., Bittencourt A.R.C., et al. Co-morbidade e mortalidade de pacientes em início de diálise. Acta Paul Enferm 2006;19(3):304-9.

7. Noël C., Dufernez F., Gerbod D., et al. Molecular phylogenies of Blastocystis isolates from different hosts: implications for genetic diversity, identification of species, and zoonosis. J Clin Microbiol 2005;43:348-55.

8. Stensvold C.R., Suresh G.K., Tan K.S., et al. Terminology for Blastocystis subtypes - a consensus. Trends Parasitol 2007;23(3):93-6.

9. Chieffi P.P., Sens Y.A.S.; Paschoalotti M.A., et al. Infection by Cryptosporidium parvum in renal patients submitted to renal transplant or hemodialysis. Rev Soc Bras Med Trop 1998;31(4):333-7.

10. Jabur P., Miorin L.A., Silva H.G.C., et al. Criptosporidiose e outras enteroparasitoses em pacientes submetidos a transplante renal ou hemodiálise. J Bras Nefrol 1996;18(3):239-42.
11. Botero J.H., Castaño A., Montoya M.N., et al. A preliminary study of the prevalence of intestinal parasites in immunocompromised patients with and without gastrointestinal manifestations. Rev Inst Med trop S. Paulo 2003;45(4):197-200.

12. Motta, M. E. F. A., Silva, G. A. P. Diarréia por parasitas. Rev Bras Saude Mater Infant 2002;2(2):117-27.

13. Rao K., Sekar U., Iraivan K.T., Abraham G., Soundararajan P. Blastocystis hominis - an emerging cause of diarrhoea in renal transplant recipients. J Assoc Physicians India 2003;51:719-21.

14. Hayashi M., Inamori M., Goto K., et al. Blastocystis hominis infection in patient with regular dialysis. J Gastroenterol 2006;41(6):605-6.

15. Salinas JL, Gonzales H.V. Infección por blastocystis. Rev Gastroenterol Peru 2007;27(3):264-74.

16. Nascimento A.S., Moitinho M.L.R. Blastocystis hominis and other intestinal parasites in a community of Pitanga City, Paraná State, Brazil. Rev Inst Med Trop São Paulo 2005;47:312-217.

17. De Carli, G.A. Parasitologia Clínica: seleção de métodos e técnicas de laboratório para o diagnóstico das parasitoses humanas. São Paulo, Brazil: Editora Atheneu, 2001.

18. Dionisio D. Cryptosporidiosis in HIV-infected patients J Postgrad Med 2002;48:215-6.

19. Cardoso L.V., Marques F.R., Cavasini CE., et al. Correlation of intestinal parasitic pathogens in HIV-seropositive adult with and without diarrhea in Northeast region of São Paulo State, Brazil. Rev Panam Infectol 2004;6(2):8-11.

20. Büyükbaba Boral O., Uysal H., Alan S., Nazlican O. Investigation of intestinal parasites in AIDS patients. Mikrobiyol Bul 2004;38(1-2):121-8.

21. Lewthwaite P., Gill G.V., Hart C.A., Beeching N.J. Gastrointestinal parasites in the immunocompromised. Curr Opin Infect Dis 2005; 18:427-35.

22. Wumba R., Enache-Angoulvant A., Develoux M., et al. Prevalence of opportunistic digestive parasitic infections in Kinshasa, Democratic Republic of Congo. Results of a preliminary study in 50 AIDS patients. Med Trop 2007;67(2):145-8.

23. Turkcapar N., Kutlay S., Nergizoglu G., et al. Prevalence of Cryptosporidium infection in hemodialysis patients. Nephron 2002;90:344-6.

24. Seyrafian S., Pestehchian N., Kerdegari M., et al. Prevalence rate of Cryptosporidium infection in hemodialysis patients in Iran. Hemod Intern 2006;10 (4):375-9.

25. Sanaka T. Nutritional effect of dialysis therapy. Artif Organs 2000;27:224-6.

26. Rhongbutsri P. Seasonal prevalence of Blastocystis hominis among patients attending Thammasat Chalermprakiat Hospital, Pathum Thani Province, Thailand. J Trop Med Parasitol 2005;28:39-42.

27. Szymanski N. Infection and Inflammation in Dialysis Patients: impact on laboratory parameters and anemia. Nephrol Nurs $\mathrm{J}$ 2001;28(3):337-40.

28. Sanepar. Abastecimento de água à população. Campo Mourão. Available in http://www.sanepar.pr.gov.br/Sanepar/internet/ siteinternet.nsf. Consulted on 29/08/2007.

29. Paula D.H.G., Cruz I. Literature review on Risk of infection in intravenous catheter related to the dialysis treatment - OBJN Club Journal. Online Brazilian Journal of Nursing (OBJN ISSN 1676-4285) 2004;3(1).

30. Alter, M. J., Tokars, J. I. Preventing transmission of infections among chronic hemodialysis patients. Nephrol Nurs J 2001;28:537-43.

31. Graczyk, T.K., Shiff C.J., Tamang L., et al. The association of Blastocystis hominis and Endolimax nana with diarrheal stools in Zambian school-age children. Parasitol Res 2005;98(1):38-43.

32. Kaya S., Cetýn E., Akçam Z., et al. Clinical symptoms in cases caused by Entamoeba coli and Blastocystis hominis. Turkiye Parazitol Derg 2005;29(4):229-31.

33. Kaya S., Cetin E.S., Aridogan B.C., Arikan S., Demirici M. Pathogenicity of Blastocystis hominis: a clinical reevaluation. Türkiye Parazitol Derg 2007;31(3):184-7.

34. Angulo I.L. Interpretação clínica e laboratorial do hemograma. Available in: pegasus.fmrp.usp.br/educacao/anemais/ interpdohemo.pdf. Consulted on 24/10/2007.

35. Breiterman-White R. Infection and inflammation in patients on dialysis: an underlying contributor to anemia and epoetin alfa hyporesponse. Nephrology Nursing Journal 2006;33(3):319-24. 